\title{
Interações universidade-empresa: um estudo exploratório sobre as empresas de biotecnologia em saúde*
}

\author{
Nathalia Guimarães Alves ${ }^{\dagger}$ \\ Marco Antônio Vargas \\ Jorge Nogueira de Paiva Britto ${ }^{\S}$
}

\begin{abstract}
Resumo
O objetivo do artigo é apresentar um panorama sobre as empresas de biotecnologia e biociências constituídas sob o modelo de empreendimentos intensivos em conhecimento no Brasil e de suas interações com a estrutura brasileira de Ciência e Tecnologia nas áreas de ciências biológicas e da saúde. O estudo está estruturado em cinco seções dedicadas à definir a biotecnologia e seu caráter "baseado em ciência" caracterizar a incipiente indústria de biotecnologia no Brasil, apresentar as evidências de incorporação da biotecnologia moderna pela indústria farmacêutica no Brasil, apontar as características da estrutura de ciência e tecnologia nas áreas de conhecimento relacionadas à biotecnologia em saúde humana e apresentar evidências de interação universidade-empresa neste segmento no Brasil. A análise está baseada em dados provenientes de diversos estudos, complementados por informações do Diretório Nacional dos Grupos de Pesquisa do Conselho Nacional de Desenvolvimento Científico e Tecnológico (CNPq) para o período 2000 e 2014. Os resultados indicam a existência de cerca de 300 empresas de biociências e 200 empresas de biotecnologia no Brasil, das quais $40 \%$ em média estão envolvidas em atividades de saúde humana. As empresas são jovens, de pequeno porte, majoritariamente controladas por capital nacional e localizadas na região sudeste do Brasil, estão em fase pré-operacional ou evolvidas na provisão de serviços tecnológicos. Há ainda indícios de que estas empresas estão fortemente relacionadas a universidades e centros de pesquisa no Brasil.
\end{abstract}

Palavras-chave: Biotecnologia, Biociências, Empreendimentos baseados em conhecimentos, Saúde humana

JEL: L26, L65, O15

\footnotetext{
*Agradecimentos ao CNPq e à CAPES pelo auxílio financeiro para realização da pesquisa.

†Professora substituta do Departamento de Economia da Universidade Federal Fluminense (UFF) e Doutoranda do Instituto de Economia da Universidade Federal do Rio de Janeiro (UFRJ)

$\ddagger$ Professor do Departamento de Economia da Universidade Federal Fluminense (UFF)

$\S$ Professor do Departamento de Economia da Universidade Federal Fluminense (UFF)
} 
32 Interações universidade-empresa: um estudo exploratório sobre as empresas de biotecnologia em saúde

\section{Introdução}

O surgimento da biotecnologia moderna, nas décadas de 1970 e 1980, representou a ruptura do paradigma tecnológico no qual se baseava a indústria farmacêutica mundial. $\mathrm{O}$ choque tecnológico impactou todos os estágios da cadeia de pesquisa, desenvolvimento e inovação (PD\&I) e originou profundas mudanças na organização das firmas e nas interações entre os atores do sistema setorial de inovação farmacêutico. O processo resultou na composição de um sistema setorial de inovação no qual a interação entre agentes heterogêneos, tais como universidades, empresas farmacêuticas e empresas dedicadas à biotecnologia são centrais para a geração de inovações.

No Brasil, o sistema biofarmacêutico envolve a presença de cinco elementos fundamentais: instituições de ciência e tecnologia (ICTs), laboratórios públicos de pesquisa e produção de fármacos e imunobiológicos, empresas dedicadas à biotecnologia em saúde humana, empresas farmacêuticas nacionais, grandes empresas farmacêuticas multinacionais instaladas no país.

O caso brasileiro envolve especificidades associadas à existência de um Sistema Único de Saúde (SUS), de caráter público e universalista, pautado pela ideia de que o acesso a saúde é um direito social. Questões demográficas de crescimento e envelhecimento da população, vinculadas a mudanças nos padrões epidemiológicos, representam pressões crescentes sobre os gastos públicos com aquisição de medicamentos e sobre padrão de dependência externa resultado da importação crescente de biofármacos de alto valor. A capacidade do Estado de implementar políticas para a promoção local de medicamentos, tais como a utilização do poder de compra do governo e a promoção de parcerias produtivas entre agentes públicos e privados, atuam como facilitadores para o crescimento e a consolidação da indústria nacional de medicamentos (GADELHA, 2012).

O fortalecimento das empresas farmacêuticas nacionais através da estratégia de produção local de medicamentos genéricos, regulada pela Lei $n^{0}$ 9789/1999, implicou em um aumento da participação das empresas nacionais no mercado farmacêutico brasileiro. Apesar dos avanços alcançados desde a implementação da lei dos genéricos, a indústria farmacêutica nacional ainda apresenta gargalos estruturais na condução de processos internos de PD\&I e na inserção no segmento de drogas terapêuticas produzidas por rotas biotecnológicas. Neste contexto, o avanço da produção nacional de medicamentos biológicos surge como uma questão estratégica nacional em função da possibilidade de inserção produtiva do país em segmentos de alto valor e do potencial alívio sobre o balanço comercial do Complexo Econômico Industrial da Saúde no Brasil, representado pela nacionalização da produção de medicamentos biológicos (VARGAS; et al, 2013).

$\mathrm{O}$ artigo elabora uma abordagem diferenciada da questão das interações entre instituições acadêmicas brasileiras e empresas de biotecnologia. A análise está focada nas empresas dedicadas à utilização da biotecnologia e empresas envolvidas na condução de pesquisa e desenvolvimento científico. Para a condução da pesquisa foram selecionados

Econômica-Niterói, v. 20, n. 1, p. 31-60. Junho, 2018 
dados de interações entre universidades e empresas disponíveis no Diretório Nacional dos Grupos de Pesquisa do Conselho Nacional de Desenvolvimento Científico e Tecnológico (CNPq) para o período 2000 e 2014.

O estudo está estruturado em cinco seções, além dessa introdução. A primeira seção apresenta uma definição sintética da biotecnologia, discutindo a sua importância para a estruturação de atividades "baseadas na ciência". A segunda seção apresenta uma caracterização da incipiente indústria de biotecnologia no Brasil, com base na sistematização de informações provenientes de diversas fontes. A terceira seção discute as evidências de incorporação da biotecnologia moderna pela indústria farmacêutica no Brasil, qualificando o caráter efetivamente "baseado em ciência" dessa indústria. A quarta seção apresenta características da estrutura de ciência e tecnologia em Biotecnologia em Saúde no Brasil, apontando evidências de interação com o setor produtivo. A quinta seção apresenta as considerações finais do artigo.

\section{Biotecnologia e atividades "baseadas em ciência"}

A biotecnologia entendida como manipulação de processos biológicos e organismos vivos para a obtenção de novos bens, processos e serviços - como a fabricação de bebidas e a transformação de alimentos - não é uma prática nova. Foi, entretanto, a partir do final da década de 1970 e início da década de 1980 que surgiu a biotecnologia moderna, uma combinação de blocos de conhecimento e ferramentas tecnológicas, cujas aplicações transversais impactaram a heurística de solução de problemas e busca por inovações em diversos setores (MCKELVEY; ORSENIGO, 2001; MAZZUCATO; DOSI, 2006).

Em uma definição ampla, a biotecnologia é descrita como a "Aplicação da ciência e da tecnologia aos organismos vivos, bem como a partes, produtos e modelos dos mesmos, para alterar materiais vivos ou não vivos com finalidade de produção de conhecimentos, produtos e serviços" (OCDE, 2005, p. 9). As atividades de biotecnologia são sintetizadas na Tabela 1.

A definição de biotecnologia fornecida pela OCDE (2005) contempla técnicas de biotecnologia moderna e tradicional. Segundo uma definição mais estreita, a biotecnologia moderna consiste em um corpo de conhecimentos e em um conjunto de tecnologias que atuam de forma integrada sobre os atributos de células, moléculas, DNA e proteínas para a criação ou modificação de produtos e processos com aplicações específicas em diversos setores de atividade (BIANCHI, 2013).

Existe uma ampla gama de terminologias e conceitos que se propõem a definir a biotecnologia moderna (BRINK; MCKELVEY; SMITH, 2004). Verifica-se na literatura a ausência de consenso sobre uma definição padrão e universal do que é a biotecnologia e sobre suas áreas de conhecimento limítrofes. A biotecnologia pode ser entendida como um termo geral que contempla um campo tecnológico emergente amparado em um amplo 
34 Interações universidade-empresa: um estudo exploratório sobre as empresas de biotecnologia em saúde

Tabela 1 - Lista de técnicas de biotecnologia definidas pela OCDE

DNA/RNA:

Cultura e engenharia de células e de tecidos:

Técnicas de processamento

Vetores gênicos e de RNA:

Bioinformática:

Nanobiotecnologia:
Genômica; farmacogenômica; sondas gênicas; engenharia genética sequenciamento, síntese e amplificação de DNA/RNA; perfil de expressão gênica; e uso de tecnologia antisense.

Proteínas e outras moléculas: Sequenciamento, síntese e engenharia de proteínas e peptídeos (inclusive hormônios de alto peso molecular); métodos de endereçamento de drogas de alto peso molecular; análise proteômica; isolamento e purificação de proteínas; sinalização e identificação de receptores celulares.

Cultura de células e tecidos; engenharia de tecidos; fusão celular; vacinas e imunomoduladores; manipulação de embriões. Fermentação utilizando bioreatores, bioprocessamento, biolixiviação, biopolpação, biobranqueamento, biodessulfurização, fitorremediação.

Terapia gênica e vetores virais.

Construção de base de dados de genomas e sequências protéicas; modelamento de processos biológicos complexos, inclusive sistemas biológicos.

Utilização de ferramentas e processos de nano e microfabricação para construção de dispositivos para o estudo de sistemas biológicos e aplicações de endereçamento de drogas; aplicações em diagnósticos e outros.

Fonte: Elaboração própria com base em OCDE (2005) e Biominas (2009).

mosaico de áreas de conhecimento científico interdisciplinares (PISANO, 2010).

A biotecnologia se encontra na fronteira tecnológica. As descobertas, as técnicas e o conhecimento científico são cumulativos e coevoluem no tempo. O processo histórico de construção e reposição da base científico-tecnológica precisa ser considerado. As novas descobertas e aplicações da biotecnologia deslocam a fronteira tecnológica, dando origem a novas oportunidades tecnológicas para o surgimento de produtos e processos que atendam as demandas da sociedade (BRINK; MCKELVEY; SMITH, 2004).

Há de se fazer uma distinção clara entre a base de conhecimentos técno-científicos e a definição de uma indústria ou setor de atividade de biotecnologia. A biotecnologia, em sentido estrito, é um conjunto de tecnologias e conhecimentos com possíveis aplicações à diversos setores industriais. Em alguns casos, é possível referir-se a existência de uma indústria de biotecnologia composta por diversas empresas, com características similares, cuja atividade principal é a condução de processos de PD\&I em biotecnologia (BRINK; MCKELVEY; SMITH, 2004).

Dado o caráter transversal das aplicações da biotecnologia, muitas áreas de atividade 
foram influenciadas pela emergência do novo paradigma tecnológico. A tabela 2 oferece uma classificação de biotecnologia por áreas de atividade.

Tabela 2 - Biotecnologia por área de atividade

\begin{tabular}{|c|c|}
\hline Saúde humana: & $\begin{array}{l}\text { Desenvolvimento de drogas e vacinas, terapia celular, pesquisas com } \\
\text { células tronco, desenvolvimento de novos vetores e fórmulas, } \\
\text { diagnósticos e proteínas recombinantes voltadas ao atendimento das } \\
\text { demandas de saúde humana. }\end{array}$ \\
\hline Saúde animal: & $\begin{array}{l}\text { Clonagem e melhoramentos genéticos, drogas e vacinas veterinárias, } \\
\text { desenvolvimento de novas tecnologias em reprodução animal. }\end{array}$ \\
\hline Agricultura: & $\begin{array}{l}\text { Biofertilizante e biopesticidas, sementes e plantas transgêneras, } \\
\text { clonagem e melhoramento genético. }\end{array}$ \\
\hline Bioenergia: & Desenvolvimento de novas tecnologias em biocombustíveis. \\
\hline Meio Ambiente: & Biorremediação, manejo de resíduos e recuperação de áreas degradadas. \\
\hline Insumos e Reagentes: & $\begin{array}{l}\text { Enzimas, reagentes para kits de diagnóstico, moléculas bioativas, } \\
\text { anticorpos. }\end{array}$ \\
\hline Misto/ Outras áreas: & $\begin{array}{l}\text { Desenvolvimento de diagnóstico celular para diversas áreas, } \\
\text { bioinformática, CROs e consultorias especializadas. }\end{array}$ \\
\hline
\end{tabular}

Fonte: CEBRAP e BRBIOTEC (2011)

Assim como muitos trabalhos que optam pelo enfoque de uma indústria ou área de aplicação específica, este artigo está, majoritariamente, voltado às atividades de biotecnologia em saúde humana inseridas no sistema de inovação da indústria farmacêutica.

O desenvolvimento de novas drogas terapêuticas por rota biotecnológica depende, em parte, da capacidade de gerar novos conhecimentos fundamentais e da expansão da compreensão sobre os processos biológicos a níveis crescentes de especialização e fragmentação do conhecimento (ORSENIGO; PAMMOLLI; RICCABONI, 2001). Utilizando como referência empírica a experiência da indústria farmacêutica e biofarmacêutica, destaca-se o caráter "baseado na ciência" das atividades biotecnológicas no segmento de saúde humana. Em setores baseados em ciência, as inovações são mais intensivas na fase de pesquisa - em relação às fases de desenvolvimento e produção - e o acesso ao conhecimento externo produzido por universidades e institutos públicos de pesquisa é crítico para a inovação. Empresas baseadas em ciência são aquelas encontradas em setores cujas fontes da tecnologia são as atividades de pesquisa e desenvolvimento conduzidas em laboratórios corporativos e baseadas no rápido desenvolvimento da ciência acadêmica (MAZZUCATO; DOSI, 2006; PAVITT, 1984).

Eliasson e Eliasson (1996) apontam a necessidade do estabelecimento de canais de comunicação entre invenções geradas no âmbito acadêmico e potenciais aplicações comerciais, através das interações entre as especialidades de cientistas acadêmicos e a experiência comercial dos cientistas alocados em laboratórios corporativos de $\mathrm{P} \& \mathrm{D}$ para viabilizar o surgimento de inovações disruptivas. A inovação biotecnológica é associada 
à construção um bloco de competência a partir de peças heterogêneas de conhecimento de áreas diversas como a fisiologia, a biologia geral, a bioquímica, a biofísica e a biologia molecular.

Um aspecto determinante para o surgimento, a sobrevivência e o crescimento de novas empresas de biotecnologia é a estreita proximidade com universidades e grupos de pesquisa. A transferência direta de tecnologia de universidades para o setor privado através da criação de novas empresas constituiu a base para o surgimento da indústria de biotecnologia no mundo. Em inúmeros casos, as empresas desfrutam de períodos de incubação em parques tecnológicos localizados dentro dos campus universitários. As universidades dispõem, frequentemente, de escritórios de transferência de tecnologia e escritórios de apoio às micro e pequenas empresas, além de facilitarem a comunicação entre as empresas e potenciais investidores. A interação com centros acadêmicos renomados representa para os novos empreendimentos uma importante fonte de credibilidade frente à parceiros comerciais e investidores institucionais (SHANE, 2004). Di Gregorio et al. (2003), Shane (2004) afirmam que as políticas de transferência de conhecimentos adotadas por universidades e centros de pesquisa influenciam diretamente a atividade empreendedora local.

A literatura acadêmica destaca a importância das universidades e centros de pesquisa para a inovação no setor produtivo de acordo com três funções: 1) Ensino e formação de recursos humanos; 2) Pesquisa e expansão da base de conhecimentos; e 3) Empreendedorismo acadêmico (MOWERY; SAMPAT, 2006; ETZKOWITZ; LEYDESDORFF, 2000; PARANHOS, 2012).

A função de ensino está diretamente relacionada à formação de recursos humanos e ao treinamento de pessoal em métodos de pesquisa. O capital humano é considerado um fator essencial para o sucesso do esforço de inovação que se dá dentro das empresas privadas. A contratação de bacharéis, graduados e pós-graduados de universidades é considerada uma forma indireta de transferência de conhecimentos da academia para o setor produtivo (MOWERY; SAMPAT, 2006). Gibbons e Johnston (1974), ao analisarem possíveis contribuições da ciência para a tecnologia, ressaltam a importância da figura do solucionador de problemas descrita sob a forma de um profissional qualificado em métodos de pesquisa capaz de identificar, viabilizar e estimular o acesso às fontes internas e, principalmente, externas de conhecimento para a solução de problemas específicos surgidos ao longo dos processos de produção e inovação. A função de pesquisa está relacionada à reposição da base de conhecimentos e à expansão de oportunidades tecnológicas, mais propensa a ocorrer nas indústrias baseadas em conhecimento (KLEVORICK et al., 1995). A função empreendedora da universidade foi proposta dentro do arcabouço teórico do modelo da tripla hélice (ETZKOWITZ; LEYDESDORFF, 2000). No modelo, o sistema de inovação assume o formato de uma estrutura interconectada composta por três esferas dinâmicas e interativas: a esfera acadêmica, o governo e a esfera produtiva. As universidades emergem como uma fonte principal de inovações disruptivas, frente ao caráter incremental dos 
avanços alcançados no âmbito das firmas individuais. Neste contexto, as universidades se articulam com o setor produtivo através de: patenteamento e licenciamento de novas peças de conhecimento para o setor produtivo; oferta de serviços de consultoria; parcerias colaborativas e criação de spin-offs acadêmicos - novas empresas criadas para explorar comercialmente peças de conhecimento geradas na academia (SHANE, 2004).

\section{A incipiente indústria de biotecnologia no Brasil: uma caracteriza- ção}

Esta seção está dedicada a quantificar e qualificar a indústria brasileira de biotecnologia através da sistematização de dados provenientes dos estudos: Bianchi (2013); ABDI (2013); CEBRAP e BRBIOTEC (2011); Biominas e PwC (2011); Biominas (2009); Biominas (2007); Biominas (2001). Os trabalhos selecionados apresentam resultados diferentes em termos de número de empresas identificadas, porém coerentes entre si na qualificação da indústria.

Em Biominas (2001), a identificação do parque nacional de empresas de biotecnologia foi realizada a partir de um diretório de empresas da Associação Brasileira de Empresas de Biotecnologia (ABRABI, 1995), conjuntamente com dados coletados pela Fundação Biominas, dando origem ao Diretório de Empresas da Biominas (2001). A definição de biotecnologia utilizada para a elaboração da lista de empresas se mostrou ampla e resultou em uma discrepância quantitativa com relação aos estudos posteriores. O estudo realizou entrevistas com 50 empresas de um universo estimado de 304 empresas. Os resultados qualitativos são compatíveis com os estudos posteriores. Em função da baixa representatividade da amostra selecionada para entrevistas, optou-se pela utilização dos resultados do estudo apenas como referência geral.

A série de estudos conduzidos pela Fundação Biominas (2007, 2009), Biominas e PwC (2011) adotou diretrizes metodológicas semelhantes. Biominas (2007) optou por uma definição de biotecnologia da revista Nature Biotechnology, segundo a qual uma empresa de biotecnologia é caracterizada pela aplicação tecnológica de organismos vivos, processos e sistemas biológicos para a realização de pesquisa e desenvolvimento e para a provisão de produtos e serviços especializados. Os estudos Biominas (2009) e Biominas e PwC (2011) utilizam a definição já apresentada de biotecnologia proposta pela OCDE (2005), assim como CEBRAP e BRBIOTEC (2011) e ABDI (2012).

Biominas (2007) defende a necessidade de diferenciação entre técnicas de biotecnologia tradicional e um conceito de biotecnologia moderna que envolva classes terapêuticas, microrganismos geneticamente modificados e projetos de pesquisa científica. O estudo optou pela exclusão de empresas cujo foco de atividade principal não envolvesse biotecnologia - empresas de consultoria, serviços e softwares - e empresas multinacionais que não realizassem produção local. Outro avanço metodológico foi a diferenciação entre 
empresas de biociências ${ }^{1}$ e empresas de biotecnologia. O levantamento de empresas foi realizado com base: no diretório de empresas da Biominas, criado em 2001; em uma pesquisa realizada pela Biominas junto a agências de fomento e através de consulta direta às incubadoras de empresas associadas à Associação Nacional de Entidades Promotoras de Empreendimentos Inovadores (ANPROTEC). Biominas (2007) não menciona a amostra de empresas utilizadas na pesquisa de campo, subentendendo que as 181 empresas identificadas responderam aos questionários.

Os estudos da Biominas (2007, 2009), Biominas e PwC (2011) optaram pela ampliação do escopo do objeto através da utilização do conceito de biociências definido como "o desenvolvimento de produtos e serviços baseados nos avanços recentes do conhecimento sobre os processos e sistemas biológicos" (Biominas, 2009, p. 9). Apesar dos termos biotecnologia e biociências serem utilizados muitas vezes como sinônimos, o conceito de biociências é mais amplo e contém a definição de biotecnologia. A justificativa para utilização do conceito de biociências é a possibilidade de inclusão de empresas voltadas à validação de medicamentos farmacêuticos através da condução de ensaios clínicos e préclínicos. O resultado é um aumento no número de empresas identificadas pelos estudos.

Biominas (2009) baseou-se em uma pesquisa de campo, realizada através do envio de questionários online às 253 empresas identificadas através da atualização do Diretório de Empresas da Biominas (2007), 102 empresas responderam ao questionário e o erro amostral estimado pelos pesquisadores é de 6,3\%. A pesquisa deu origem ao Diretório de Empresas de Biociências (Biominas, 2009).

O estudo Biominas e PwC (2011) seguiu as diretrizes metodológicas definidas em seu predecessor. Questionários foram enviados às 271 empresas identificadas e 103 respostas foram obtidas. Estimou-se para a pesquisa um erro amostral de 6,5\% em um intervalo de confiança de $90 \%$. O esforço resultou na elaboração de um Diretório de Empresas de Biociências de 2011.

No mesmo ano, foi divulgado o mapeamento das empresas de biotecnologia CEBRAP e BRBIOTEC (2011). O estudo, considerado metodologicamente mais consistente, disponibiliza uma lista com 176 nomes $^{2}$ de empresas e instituições que participaram da pesquisa e o número de respostas obtidas cada item do questionário. $O$ estudo partiu de uma lista de 900 nomes de empresas, incubadoras e instituições fornecida pelo Ministério do Desenvolvimento Indústria e Comércio $(\mathrm{MDIC})^{3}$, filtrada a partir da definição de biotecnologia da OCDE (2005). O estudo optou pela inclusão das empresas especializadas na validação de medicamentos, transformando-se essencialmente em um estudo de biociências.

Em 2012, o estudo da Agência Brasileira de Desenvolvimento Industrial (ABDI, 2012) questionou 106 empresas envolvidas na utilização de biotecnologia. O levanta-

\footnotetext{
${ }^{1} \mathrm{O}$ conceito de biociências é formalmente apresentado em Biominas (2009)

${ }^{2}$ Apesar da identificação de 243 empresas, a lista divulgada com apenas 176 nomes.

${ }^{3}$ Atual Ministério da Indústria, Comércio Exterior e Serviços.
} 
mento foi realizado com base em listas de empresas disponibilizadas pelo MDIC, e pela própria $\mathrm{ABDI}$ através de consultas às incubadoras e parques tecnológicos brasileiros. Utilizou-se, ainda, o estudo Bianchi (2013) baseado na consolidação de dados sobre a indústria de biotecnologia da Pesquisa de Inovação (PINTEC) do Instituto Brasileiro de Geografia e Estatística (IBGE) e dos estudos da Biominas, além de uma identificação de empresas dedicadas à biotecnologia ${ }^{4}$ conduzida pelo autor.

Estima-se que existam, atualmente, no país um número em torno de 271 a 338 empresas de biociências e entre 175 a 240 empresas de biotecnologia (Tabela 3). O número de empresas com aplicações em saúde humana é igual ou superior a 78 empresas de biociências e 49 empresas de biotecnologia. O número máximo de empresas de biotecnologia em saúde humana (94) supera o número máximo de empresas de biociências em saúde humana (89) em um mesmo ano. A constatação reflete uma inconsistência teórica visto que a definição de biotecnologia está contida na definição de biociências. O paradoxo explicita as dificuldades envolvidas na compatibilização de estudos que utilizam definições e metodologias distintas para a identificação de empresas inseridas em atividades tecnológicas complexas, interdisciplinares e dinâmicas.

Tabela 3 - Número de empresas de biociências e biotecnologia no Brasil (2001 - 2013)

\begin{tabular}{lcccc}
\hline Fonte & $\begin{array}{c}\text { Empresas de } \\
\text { de Biociências }\end{array}$ & $\begin{array}{c}\text { Empresas } \\
\text { de Biotecnologia }\end{array}$ & $\begin{array}{c}\text { Empresas } \\
\text { de biociências em } \\
\text { saúde humana }\end{array}$ & $\begin{array}{c}\text { Empresas } \\
\text { de biotecnologia } \\
\text { em saúde humana }\end{array}$ \\
\hline Bianchi (2013) & 338 & 175 & - & 64 \\
ABDI (2012) & - & 240 & - & 49 \\
CEBRAP e BRBIOTEC & - & 237 & - & 94 \\
$(2011)$ & 271 & 143 & 89 & - \\
Biominas e PwC & 253 & 109 & 78 & - \\
$(2011)$ & 181 & 71 & - & 12 \\
Biominas (2009) & - & 304 & - & 70 \\
Biominas (2007) & & & & \\
Biominas (2001) & & & & \\
\hline
\end{tabular}

Fonte: Elaboração própria com base nos estudos listados na tabela.

É possível uma avaliação das empresas brasileiras por área de atividade, conforme mostrado na Tabela 4. Observa-se, ao longo dos anos, um aumento na proporção de empresas voltadas às atividades em saúde humana, área que reúne a maior proporção de empresas de biociências e biotecnologia brasileiras (34\% em média). Outras áreas que se destacam no país são: saúde animal ( $22 \%$ em média); agricultura ( $18 \%$ em média) e insumos e reagentes (17\% em média).

As empresas brasileiras de biotecnologia e biociências são, majoritariamente, jovens

\footnotetext{
${ }^{4}$ Empresas cuja atividade principal envolve o uso da biotecnologia (OCDE, 2005)
} 
40 Interações universidade-empresa: um estudo exploratório sobre as empresas de biotecnologia em saúde

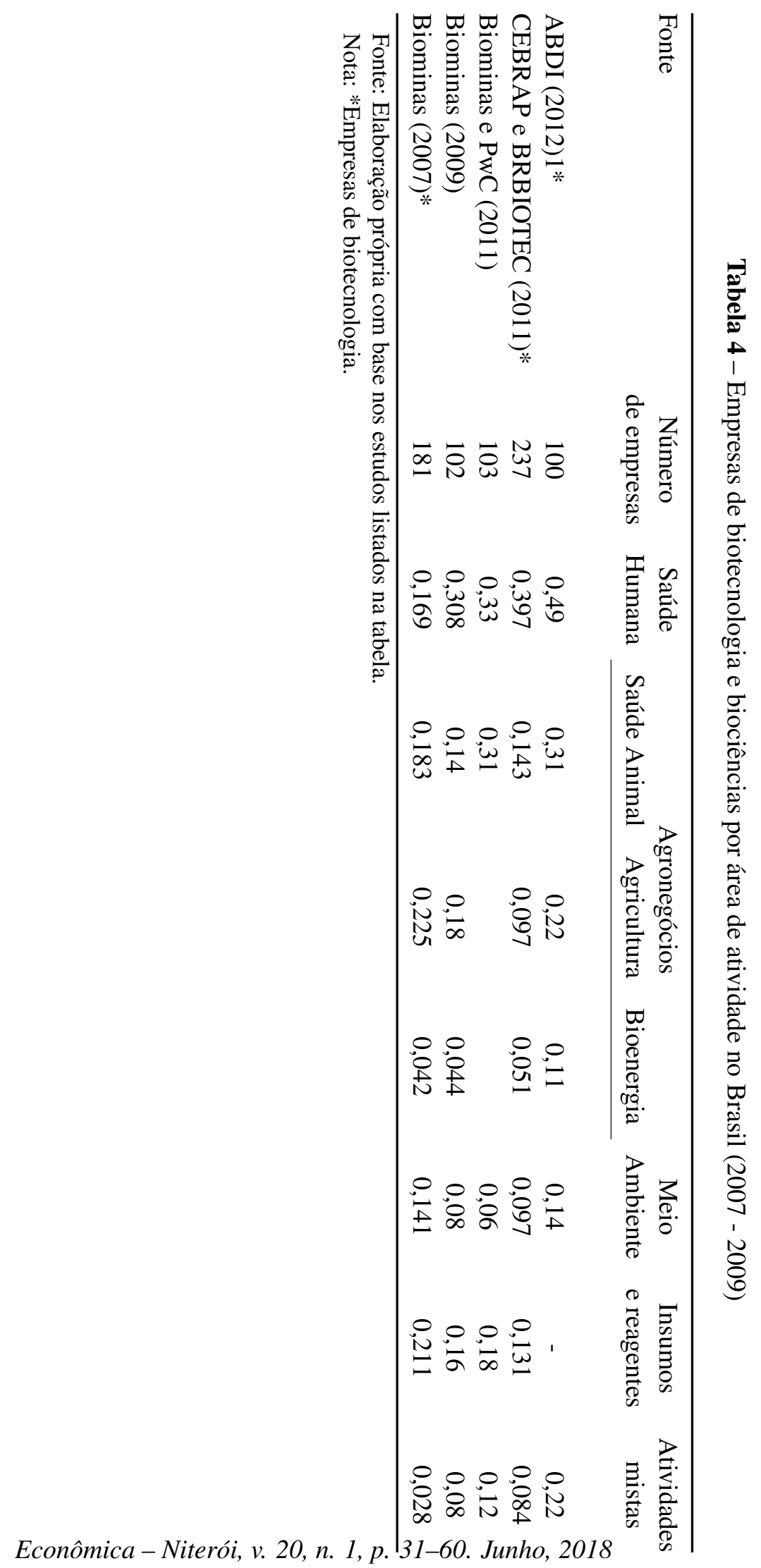


(Tabela 5). Os estudos da Fundação Biominas indicam que entre 32\% e 51\% das empresas possuem até 5 anos de funcionamento. Os estudos revisados apontam que cerca de $70 \%$ das empresas têm até 10 ou 12 anos de idade. As empresas foram criadas, majoritariamente, após o ano 2000. O cálculo de anos de vida foi feito com relação à data de divulgação de cada estudo. Não é possível avaliar se há um processo de envelhecimento ou de renovação da população de empresas com base em amostras díspares.

Tabela 5 - Empresas de biotecnologia e biociências no Brasil por idade \% (2007 - 2013)

\begin{tabular}{|c|c|c|c|c|c|c|}
\hline \multirow[t]{2}{*}{ CEBRAP e BRBIOTEC (2011)* } & \multirow{2}{*}{$\begin{array}{c}\mathrm{N} \\
214\end{array}$} & \multicolumn{4}{|c|}{ Até 11 anos } & \multirow[t]{2}{*}{ Acima de 11 anos } \\
\hline & & 0 & & 0,27 & & \\
\hline \multirow[t]{2}{*}{ Bianchi (2013)* } & \multirow[b]{2}{*}{92} & \multicolumn{2}{|c|}{ Até 7 anos } & \multicolumn{2}{|c|}{$8-12$ Anos } & Acima de 13 anos \\
\hline & & \multicolumn{2}{|c|}{0,32} & \multicolumn{2}{|c|}{0,36} & 0,28 \\
\hline \multirow[t]{2}{*}{ Biominas e PwC (2011) } & & $\begin{array}{l}\text { Até } 2 \\
\text { anos }\end{array}$ & $\begin{array}{l}2-5 \\
\text { Anos }\end{array}$ & $\begin{array}{l}5-10 \\
\text { Anos }\end{array}$ & $\begin{array}{c}10-15 \\
\text { Anos }\end{array}$ & $\begin{array}{c}\text { Acima de } \\
15 \text { anos }\end{array}$ \\
\hline & 103 & 0,06 & 0,38 & 0,29 & 0,09 & 0,18 \\
\hline Biominas (2009) & 102 & 0,125 & 0,198 & 0,354 & 0,156 & 0,167 \\
\hline Biominas $(2007) *$ & 181 & 0,267 & 0,239 & 0,211 & 0,099 & 0,183 \\
\hline
\end{tabular}

Fonte: Elaboração própria com base nos estudos listados na tabela.

Nota: *Empresas de biotecnologia. N-Número de empresas

Existem duas alternativas para avaliar o tamanho de uma empresa: o faturamento bruto anual e o número de funcionários. Seguindo a definição legal de porte por faturamento ${ }^{5}$, cerca de 50\% dos empreendimentos brasileiros de biociências são microempresas. O percentual conjunto de micro e de pequenas empresas é, em média, superior a 70\% (Tabela $6)$.

O Serviço Brasileiro de Apoio às Micro e Pequenas Empresas (SEBRAE) propõe a utilização do número de funcionários como um indicador para o tamanho da empresa. Consideram-se microempresas aquelas que empregam até 19 funcionários; pequenas aquelas com 20 a 99 funcionários; médias aquelas com 100 a 499 funcionários; e grandes as empresas com mais de 500 funcionários. A Tabela 7 mostra que o percentual de microempresas é estimado entre $68 \%$ e $78 \%$, enquanto o percentual de empresas pequenas varia entre $17 \%$ e $25 \%$. Ou seja, as micro e pequenas empresas constituem mais de $90 \%$ da indústria de biociências e biotecnologia brasileira.

O estudo da ABDI (2012) fornece uma caracterização das empresas por técnica ou aplicação da biotecnologia. Das 100 empresas que tiveram suas respostas analisadas: 67

\footnotetext{
${ }^{5}$ De acordo com a Lei Complementar No123 de 14 de dezembro de 2006, são consideradas microempresas aquelas empresas que auferem receita bruta anual igual ou inferior a $\mathrm{R} \$ 360.000,00$ reais. Empresas de pequeno porte são aquelas cuja receita bruta anual entre $\mathrm{R} \$ 360.000,00$ e $\mathrm{R} \$ 3.600 .000,00$ reais (BRASIL, 2006).
} 
42 Interações universidade-empresa: um estudo exploratório sobre as empresas de biotecnologia em saúde

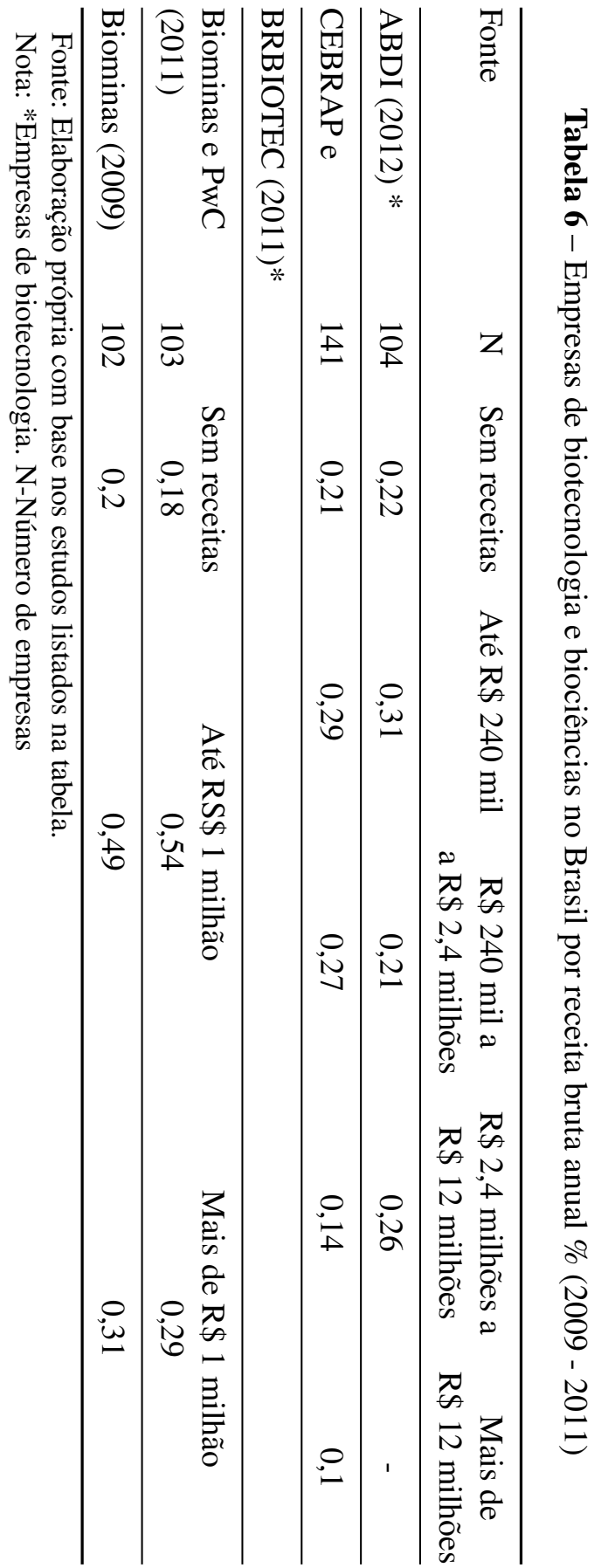

Econômica-Niterói, v. 20, n. 1, p. 31-60. Junho, 2018 
Tabela 7 - Empresas de Biociências no Brasil por número de empregados \% (2009 - 2012)

\begin{tabular}{lcccccc}
\hline Fonte & $\mathrm{N}$ & Até 10 & 11 a 20 & 21 a 50 & 51 a 100 & Mais de 100 \\
\hline Abdi (2012)* & 96 & 0,65 & 0,12 & \multicolumn{2}{c}{0,17} & 0,07 \\
Cebrap e Brbiotec (2011)* & 138 & 0,46 & 0,19 & 0,2 & 0,06 & 0,09 \\
Biominas e PwC (2011) & 103 & 0,53 & 0,13 & 0,21 & 0,07 & 0,06 \\
Biominas (2009) & 102 & 0,51 & 0,27 & 0,14 & \multicolumn{2}{c}{0,08} \\
\hline
\end{tabular}

Fonte: Elaboração própria com base nos estudos listados na tabela.

Nota: *Empresas de biotecnologia. N-Número de empresas

afirmaram utilizar mais de uma técnica; 24 sinalizaram a utilização de apenas uma técnica; e 9 não indicaram qualquer aplicação. Uma parcela significativa das empresas declarou a utilização de técnicas de engenharia genética (DNA e RNA); processamento biotecnológico (fermentação, biofiltragem e biorremediação); síntese de proteínas; manipulação de moléculas; e engenharia de tecidos vivos (Tabela 8). As técnicas de biotecnologia foram utilizadas com maior frequência nas etapas de $\mathrm{P} \& \mathrm{D}$ de produtos e processos, e com menor frequência na fase de produção. A reduzida frequência na etapa de produção é compatível com um cenário de empresas em fase pré-operacional.

Tabela 8 - Empresas por atividades em biotecnologia no Brasil (2012)

\begin{tabular}{lccc}
\hline & $\begin{array}{c}\text { Usa técnica } \\
\text { em pesquisas }\end{array}$ & $\begin{array}{c}\text { Usa técnica no produto ou no } \\
\text { desenvolvimento de processos } \\
\text { processos }\end{array}$ & $\begin{array}{c}\text { Usa técnica } \\
\text { na produção }\end{array}$ \\
\hline DNA/RNA & 0,41 & 0,4 & 0,24 \\
$\begin{array}{l}\text { Proteínas e outras moléculas } \\
\text { Células, cultura e engenharia }\end{array}$ & 0,35 & 0,28 & 0,16 \\
$\begin{array}{l}\text { de tecidos } \\
\text { Técnicas de processamento }\end{array}$ & 0,3 & 0,27 & 0,1 \\
biotecnológico & 0,32 & 0,32 & 0,22 \\
$\begin{array}{l}\text { Gene e vetores de RNA } \\
\text { Bioinformática }\end{array}$ & 0,11 & 0,05 & 0,03 \\
Nanobiotecnologia & 0,22 & 0,19 & 0,07 \\
\hline
\end{tabular}

Fonte: Retirado de (ABDI, 2012)

Nota: Número de empresas $=100$.

A tendência é confirmada no caso de empresas de atuam na área de saúde humana. Uma parcela maior das empresas possui aplicações em estágio de pesquisa e desenvolvimento (P\&D) e poucas empresas possuem produtos no mercado ou em fase de aprovação regulatória, especialmente no caso de empresas com aplicações em grandes moléculas (Tabela 9). 
$44 \quad$ Interações universidade-empresa: um estudo exploratório sobre as empresas de biotecnologia em saúde

Tabela 9 - Estágio atual das aplicações biotecnológicas em Saúde Humana no Brasil (2012)

\begin{tabular}{lcc}
\hline & $\begin{array}{c}\text { Saúde humana } \\
\text { (moléculas grandes) }\end{array}$ & $\begin{array}{c}\text { Saúde humana } \\
\text { (outros) }\end{array}$ \\
\hline P\&D & 0,23 & 0,34 \\
Testes pré-clínicos & 0,1 & 0,16 \\
Fase regulatória (em fase de registro) & 0,03 & 0,1 \\
Produto no mercado (em produção) & 0,01 & 0,11 \\
\hline
\end{tabular}

Fonte: ABDI (2012)

A importância das interações com universidades e centros de pesquisa brasileiros para o surgimento e viabilização das empresas de biociências e de biotecnologia é destacada em todos os estudos revisados. Contudo, apenas dois documentos forneceram estatísticas sobre interações universidade-empresa: CEBRAP e BRBIOTEC (2011) e Biominas (2009). De acordo com CEBRAP e BRBIOTEC (2011), cerca de 95\% das empresas de biotecnologia brasileira mantiveram interações ativas com ICTs. Enquanto, 70\% das empresas mantinham relacionamentos formalizados com as instituições acadêmicas (Tabela $10)$.

Tabela 10 - Empresas de Biociências no Brasil - Relacionamentos UniversidadeEmpresa \% (2009 - 2011)

\begin{tabular}{lccccc}
\hline Fonte & $\begin{array}{c}\text { Número } \\
\text { de } \\
\text { empresas }\end{array}$ & \multicolumn{2}{c}{$\begin{array}{c}\text { Possui relacionamento } \\
\text { com } \\
\text { universidade? }\end{array}$} & $\begin{array}{c}\text { Possui relacionamento } \\
\text { formal com } \\
\text { universidade? }\end{array}$ \\
\hline Cebrap e & 145 & 0,945 & 0,055 & 0,7 & $\begin{array}{c}\text { Não } \\
\text { Brbiotec }(2011)^{*}\end{array}$ \\
Biominas $(2009)$ & 102 & - & - & 0,73 & 0,27 \\
\hline
\end{tabular}

Fonte: Elaboração própria com base nos estudos listados na tabela.

Nota: *Empresas de biotecnologia.

Entre os tipos de relacionamentos frequentes apontados pelas empresas se destacam: parcerias para o desenvolvimento conjunto de produtos e processos; a utilização da estrutura física das universidades; a contratação de estudantes e serviços especializados; o licenciamento de tecnologias e o treinamento de pessoal (Tabela 11).

Incubadoras e parques tecnológicos são apontados como fatores críticos para o surgimento e a sobrevivência das empresas brasileiras de biotecnologia e biociências por proporcionarem um ambiente protegido e propício para o desenvolvimento de novos projetos. A Tabela 12 indica que parcelas relativamente altas (entre 50\% e 60\%) das empresas

Econômica-Niterói, v. 20, n. 1, p. 31-60. Junho, 2018 
Tabela 11 - Tipos de relacionamento universidade-empresa no Brasil \% (2009 - 2011)

\begin{tabular}{lcc}
\hline & Cebrap e Brbiotec $(2011)^{i}$ & ${\text { Biominas }(2009)^{i i}}$ \\
\hline $\begin{array}{l}\text { Co-desenvolvimento de produtos } \\
\text { ou processos }\end{array}$ & 0,765 & 0,137 \\
Licenciamento de tecnologias & - & 0,253 \\
Compartilhamento de infraestrutura & 0,522 & 0,337 \\
(empresas utilizando a estrutura da universidade) & 0,522 & 0,337 \\
Contratação de serviços especializados & 0,441 & 0,253 \\
Contratação de estudantes e bolsistas & & 0,253 \\
Treinamento de pessoal ou consultoria & 0,419 & - \\
de pesquisadores & 0,419 & - \\
Cursos, conferências e outros & 0,221 & 0,095 \\
\hline
\end{tabular}

Fonte: Elaboração própria com base nos estudos listados na tabela.

Nota: *Empresas de biotecnologia.

${ }^{i} \mathrm{~N}=145$

${ }^{i i} \mathrm{~N}=102$

de biotecnologia e biociências estavam incubadas ou eram empresas graduadas na época em que os estudos foram realizados. Estudos que utilizaram a definição mais abrangente de biociências apresentam parcelas menores de empresas incubadas em comparação aos estudos que adotam definições de biotecnologia. A constatação fica explícita no caso da Biominas (2007) que fornece porcentagem tanto para empresas de biociências incubadas (27\%), quanto para empresas de biotecnologia incubadas (35\%).

Um dos principais gargalos para o desenvolvimento da indústria brasileira de biotecnologia é o acesso à infraestrutura adequada às necessidades do segmento, especialmente no que se refere às exigências regulatórias de certificação e boas práticas laboratoriais (Biominas. PwC, 2011). Poucas incubadoras brasileiras possuem infraestrutura adequada às exigências do setor de biotecnologia, principalmente na área de saúde humana.

Tabela 12 - Relação com Incubadoras no Brasil (2007 - 2013)

\begin{tabular}{lcccc}
\hline Fonte & Incubadas & Graduadas & Nunca estiveram incubadas & N \\
\hline Bianchi (2013)* & \multicolumn{2}{c}{0,604} & 0,396 & 92 \\
Cebrap e Brbiotec (2011)* & 0,303 & 0,2 & 0,497 & 145 \\
Biominas (2009) & 0,19 & 0,162 & 0,648 & 102 \\
Biominas (2007) & 0,271 & \multicolumn{2}{c}{0,729} & 181 \\
& 35,21 & \multicolumn{2}{c}{0,648} & $71^{*}$ \\
\hline
\end{tabular}

Fonte: Elaboração própria com base nos estudos listados na tabela.

Nota: *Empresas de biotecnologia. N - Número de empresas.

As alianças de colaboração estão associadas a processos de transferência de tecnolo- 
46 Interações universidade-empresa: um estudo exploratório sobre as empresas de biotecnologia em saúde

gia. A Tabela 13 mostra a baixa utilização de mecanismos de transferência de tecnologia, especialmente entre empresas. Cerca de 23 empresas licenciaram alguma patente de universidades e centros de pesquisa. O número de empresas que realizaram algum tipo de inovação aberta com outras empresas é um pouco maior, cerca de 30 empresas. O licenciamento de patentes entre empresas é quase inexistente no país. O único fator de transferência de tecnologia realmente utilizado pelas empresas é o compartilhamento da infraestrutura de universidades e centros de pesquisa. A maior proximidade entre os pesquisadores tende a aumentar a transferência de conhecimentos tácitos e a colaboração na solução de problemas característicos do processo de inovação, contudo "as empresas apontam a morosidade dos processos internos das ICTs como a principal dificuldade no licenciamento de tecnologias e no estabelecimento de contratos de parceria com ICTs" (ABDI, 2012: p. 20).

Tabela 13 - Transferência de tecnologia: patentes e outras modalidades no Brasil (2012)

\begin{tabular}{lccc}
\hline & Sim & Não & Não respondeu \\
\hline Licenciou patente de alguma ICT brasileira? & 0,22 & 0,74 & 0,04 \\
Licenciou patente de outra empresa? & 0,08 & 0,86 & 0,06 \\
Licenciou patente para outra empresa? & 0,05 & 0,86 & 0,09 \\
Já fez inovação aberta com outra empresa? & 0,28 & 0,59 & 0,13 \\
Utiliza infraestrutura de ICT & 0,61 & 0,32 & 0,07 \\
\hline
\end{tabular}

Fonte: ABDI (2012).

Nota: Número de empresas $=106$.

\section{Biotecnologia e indústria farmacêutica no Brasil: evidências do ca- ráter "baseado em ciência"}

Desde a década de 1980, o sistema farmacêutico mundial sofreu profundas transformações que impactaram as condições de entrada na indústria, o comportamento estratégico e as trajetórias de crescimento das firmas. Por um lado, o aumento da intensidade e dos custos $\mathrm{P} \& \mathrm{D}$ e marketing induziram processo de fusões e aquisições, aumentando a concentração e a globalização da indústria. Por outro lado, observou-se a emergência de um novo padrão de colaboração nas cadeias de PD\&I envolvendo articulações entre empresas farmacêuticas estabelecidas, empresas dedicadas à biotecnologia em saúde humana, ICTs e instituições governamentais (MCKELVEY; ORSENIGO, 2001).

O sistema biofarmacêutico brasileiro está configurada em torno da presença de cinco elementos fundamentais: as universidades e centros de pesquisa, os laboratórios oficias de pesquisa e produção de medicamentos e imunobiológicos, as empresas de biotecnologia,

Econômica-Niterói, v. 20, n. 1, p. 31-60. Junho, 2018 
e biociências em saúde humana, empresas farmacêuticas multinacionais instaladas no país e as empresas farmacêuticas brasileiras.

As universidades e o centros de pesquisa, apesar de não se dedicarem à produção direta de produtos e serviços farmacêuticos, constituem um elemento do sistema de inovação biofarmacêutico brasileiro devido às funções que exercem de pesquisa e capacitação de recursos humanos. Albuquerque e Cassiolato (2002) argumentam que além da formação de profissionais, as universidades agem com um centro de convergência de fluxos de informação provenientes não apenas de suas próprias pesquisas, mas também de interações com empresas, agências regulatórias, hospitais, clínicas, postos médicos entre outros atores capazes de transmitir novas demandas à indústria farmacêutica.

Os laboratórios oficiais de pesquisa e produção de fármacos e imunobiológicos como o Instituto Biomanguinhos e o Instituto Butantan - são responsáveis por atender cerca de $80 \%$ da demanda doméstica por vacinas (GADELHA, 2012). O Brasil conta com 16 laboratórios públicos em funcionamento que são responsáveis por cerca de $3 \%$ em valor da produção nacional de fármacos e medicamentos e $10 \%$ em volume de produção (ABDI, 2013).

As grandes empresas farmacêuticas multinacionais, que dominam o mercado mundial, possuem elevada participação no mercado farmacêutico nacional. Apesar de trazerem ao país as etapas de produção e distribuição, as multinacionais mantêm seus esforços inovadores concentrados em suas matrizes no exterior. Historicamente, as atividades PD\&I das multinacionais no país se restringem à adaptação da produção à utilização de insumos locais e à adequação às exigências fitossanitárias brasileiras. Com isso, as grandes assimetrias tecnológicas e barreiras à entrada no setor farmacêutico tendem a se perpetuar. Observou-se ao longo das décadas de 1970 e 1980, o predomínio das empresas multinacionais que dominavam $75 \%$ a $85 \%$ do mercado brasileiro de medicamentos (PARANHOS, 2012).

A introdução no país da lei dos Genéricos, lei no 9789/1999, representou um ponto de inflexão para a indústria farmacêutica nacional ao regular o registro de cópias de medicamento não protegidos por patentes mediante aprovação pela Agência Nacional de Vigilância Sanitária (ANVISA). A introdução do segmento de genéricos impulsionou processos locais de aprendizagem tecnológica e resultou no aumento da participação nacional no mercado local de 32\% em 2003 para mais de 50\% em 2010 e (PARANHOS, 2012; GADELHA, 2012) . Apesar dos avanços alcançados, a indústria farmacêutica nacional ainda apresenta gargalos estruturais na condução de processos internos de PD\&I e na inserção no segmento de fármacos produzidos por rota biotecnológica (VARGAS; et al, 2013). A estratégia de especialização em medicamentos genéricos, cuja informação tecnológica encontra-se codificada em documentos de patentes, limita a capacidade de inovação das empresas que tendem a investir pouco em esforços de PD\&I (PARANHOS, 2012).

Identifica-se, a partir de 2008, uma mudança no padrão inovativo das empresas brasileiras relacionada ao aumento na realização de atividades internas de P\&D e nos valo- 
res gastos nestas atividades entre 2008 e 2011 (PARANHOS. HASENCLEAVER, 2014; VARGAS. BRITTO, 2015). Destaca-se o esforço de inserção das empresas farmacêuticas nacionais no segmento de medicamentos biológicos, apoiado pelo governo brasileiro através da política de Parcerias para o Desenvolvimento Produtivo (GOMES, 2014). A política de Parcerias para o Desenvolvimento Produtivo (PDPs) coordenada pelo ministério da saúde foi desenhada para promover a transferência tecnológica entre laboratórios oficiais e empresas farmacêuticas privadas com o objetivo de internalizar a produção de fármacos, biofármacos e equipamentos médicos considerados estratégicos para atender as demandas do SUS (VARGAS. BRITTO, 2015).

A estratégia das farmacêuticas brasileiras está direcionada à produção local de medicamentos biossimilares ou bioequivalentes. Os medicamentos biossimilares são definidos como "quase cópias" de biofármacos com patentes expiradas. Em função das especificidades tecnológicas envolvidas na produção de biológicos, não é possível a replicação perfeita do medicamento com base da informação codificada nos documentos de patente. A realização de cópias exige que as empresas possuam competências e capacitações científicas e tecnológicas na produção de drogas por rotas biotecnológicas.

Existe uma dicotomia criada pelo modelo brasileiro de inserção em biofármacos através de grandes empresas produtoras de biossimilares e o modelo de pequenas empresas spin-offs acadêmicos - descrito na literatura internacional sobre biotecnologia em saúde humana. Dois argumentos sustentam a opção pelo estímulo às grandes empresas: (i) a criação de empresas âncora, capazes de gerar incentivos para o surgimento de pequenas empresas de biotecnologia dedicadas à condução de PD\&I; (ii) a capacidade de atuação do governo no estimulo à produção local através de licitações de compras governamentais associadas à existência de economias de escala em produção e distribuição das grandes farmacêuticas (Gomes 2014). Independente do porte das empresas, há um consenso na literatura sobre a importância da construção de capacitações em ciência e tecnologia e das interações sistêmicas entre empresas, universidades e laboratórios oficiais para o sucesso da estratégia brasileira de inserção no segmento de produtos biofarmacêuticos.

\section{Biotecnologia em Saúde: Estrutura científico-tecnológica e evidên- cias de interação com o setor produtivo}

O Brasil possui uma ampla gama de instituições acadêmicas com grupos de pesquisa consolidados em ciências biológicas e da saúde. Observa-se no país um aumento significativo no número de pesquisadores em cursos de pós-graduação em biociências ao longo do período 2000-2014. Destaca-se o papel desempenhado pelos programas da Coordenação de Aperfeiçoamento de Pessoal de Nível Superior (CAPES) e do Conselho Nacional de Desenvolvimento Científico e Tecnológico (CNPq) para a formação de pessoal em métodos e técnicas avançadas (VARGAS; et al, 2016).

Econômica-Niterói, v. 20, n. 1, p. 31-60. Junho, 2018 
Para avaliar a evolução da estrutura brasileira de ciência e tecnologia em biociências, foram selecionados dados extraídos do Diretório dos Grupos de Pesquisa do Conselho Nacional de Desenvolvimento Científico e Tecnológico (CNPq) em áreas de conhecimentos selecionadas: Bioquímica, Biofísica, Biologia Geral, Genética, Imunologia, Medicina, Microbiologia, Morfologia, Parasitologia, Farmacologia, Farmácia e Fisiologia. As estatísticas do Diretório dos grupos de Pesquisa do CNPq estão disponíveis de acordo com censos bianuais realizados entre 2000 e 2010 e um censo realizado em 2014.Os dados, organizados na Tabela 14 indicam uma trajetória de crescimento e fortalecimento dos grupos de pesquisa alocados em áreas de conhecimento sensíveis para a consolidação da cadeia de PD\&I da indústria farmacêutica e biofarmacêutica nacional. O número de grupos de pesquisa passou de 2.095 no ano 2000 para $4.683 \mathrm{em} 2014$, refletindo uma taxa de crescimento médio bianual de $15 \%$. O crescimento das linhas de pesquisa e do número de pesquisadores foi ainda mais intenso, alcançando taxas médias de crescimento de $21 \%$ e $25 \%$, respectivamente, no mesmo período. O número total de pesquisadores registrados nos grupos de pesquisa alcançou a marca de 37.694 no ano 2014, contudo a base de dados do CNPq está sujeita a um problema de dupla contagem visto que cada pesquisador pode ser registrado em até três grupos de pesquisa diferentes. Apesar das limitações da base de dados, o diretório do CNPq representa um dos melhores indicadores da estrutura científico-tecnológica do Brasil.

Apesar do crescimento expressivo de grupos de pesquisa, linhas de pesquisa e pesquisadores nas áreas de conhecimento selecionadas, há limitações e fragilidades em termos de construção de capacitações nessas áreas. $\mathrm{O}$ crescimento médio das áreas de conhecimento selecionadas é solapado pelo crescimento das demais áreas de conhecimento do CNPq, especialmente: Administração; Artes; Comunicação; Desenho Industrial; Direito e Educação Física. A perda média estimada de participação das áreas selecionadas em relação aos totais do CNPq no período 2000-2014 é de - 4,8\% em relação ao número de grupos de pesquisa; - $3 \%$ em relação às linhas de pesquisa e $-2,7 \%$ em relação ao número de pesquisadores.

Apesar da participação relativa decrescente das áreas selecionadas no total do CNPq, a Tabela 13 mostra uma composição dos grupos de pesquisa em áreas selecionadas continuamente mais intensiva em pesquisadores com título de doutorado. Entre 2000 e $2010^{6}$ houve um aumento do número de pesquisadores em todos os níveis de especialização. $\mathrm{O}$ crescimento médio do número de doutores $(26 \%)$ foi superior ao crescimento relativo dos outros níveis educacionais (em média de 10\%). O percentual de doutores é substancialmente superior nas áreas selecionadas (em média 76\%) se comparado às demais áreas de conhecimento do CNPq (em média 65\%).

Um ponto crítico para desenvolvimento de produtos de base biotecnológica é a existência de um gargalo na transferência de peças de conhecimento científico produzidas na academia para setor produtivo. A importância do transbordamento de conhecimentos en-

${ }^{6}$ Último ano disponível para a série de dados. 
50 Interações universidade-empresa: um estudo exploratório sobre as empresas de biotecnologia em saúde

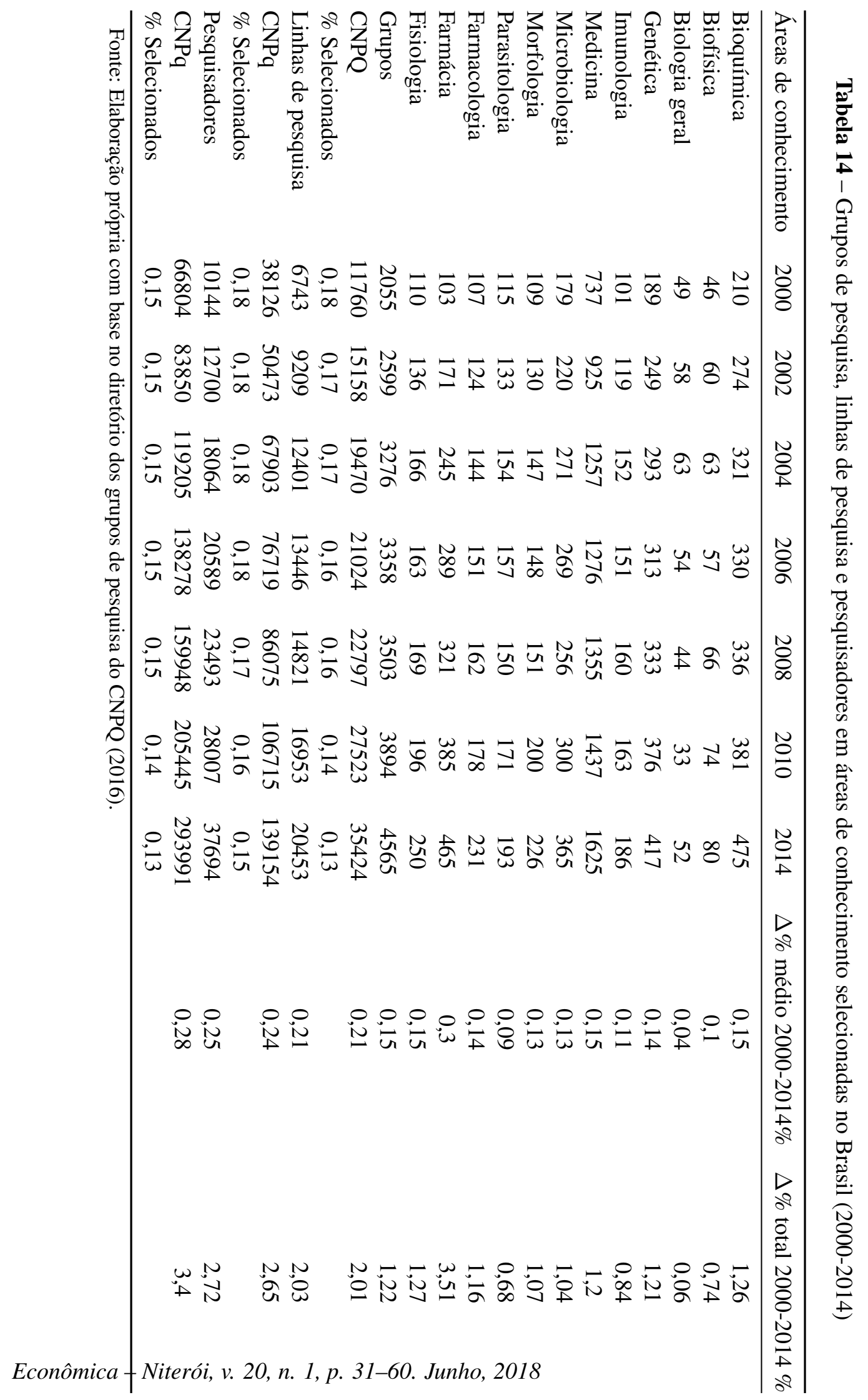


tre as duas esferas pode ser justificada com base em três argumentos: (i) A necessidade de adequação e desenvolvimento local de novos produtos que atendam às exigências regulatórias e fitossanitárias brasileiras; (ii) A importância do fortalecimento de relações cooperativas para a efetiva integração de agentes setoriais à estrutura do Complexo Econômico Industrial da Saúde (CEIS); e (iii) A importância dos transbordamentos para a construção de competências e capacitações tecno-científicas para o desenvolvimento de inovações farmacêuticas e biofarmacêuticas (VARGAS et al, 2016).

A Tabela 15 mostra que o número de grupos de pesquisa em áreas de conhecimento selecionadas que interagiram com empresas e instituições cresceu, em média, $31 \%$ no período $2002^{7}-2010$ e $81 \%$ no período 2002-2014. Destaca-se o crescimento extraordinário das interações em áreas selecionadas entre 2010 e 2014 (285\%), acima do crescimento também acentuado das demais áreas do CNPq (167\%). A ausência dos dados de 2014 no plano tabular do diretório do CNPq impede uma avaliação sobre a qualidade dos dados para este ano específico. Mesmo que o ano 2014 seja descartado da série, a trajetória do período 2002-2010 é suficiente para indicar um aumento substancial das interações entre a esfera acadêmica e o setor industrial.

A Tabela 17 mostra o crescimento médio de $34 \%$ do número de empresas e instituições que interagiram com os grupos de pesquisa cadastrados no CNPq no período 2002-2010 ${ }^{8}$. O fato do crescimento do número de empresas interativas (34\%) ser superior ao crescimento do número de grupos interativos (31\%) indica um aumento na taxa de interação por grupo de pesquisa.

A Tabela 18 mostra a análise das interações universidade-empresa por tipo de relacionamento para o ano de $2010^{9}$. Foram identificados 1164 tipos de relacionamentos em áreas de conhecimento selecionadas. Os tipos de interações mais frequentes foram: esforços conjuntos para o desenvolvimento de pesquisas básica e aplicada, contratos de transferência de tecnologia do grupo para o parceiro e fornecimento de insumos do parceiro para o grupo. Ressalta-se a necessidade de canais institucionalizados e contínuos de transferências de informação em vias de mão dupla (tanto do grupo para o parceiro, quanto do parceiro para o grupo) para que as interações sejam bem sucedidas na troca e apropriação do conhecimento.

Uma avaliação cautelosa da lista com nomes de empresas e instituições interativas em áreas de conhecimento selecionadas, divulgada pelo diretório do $\mathrm{CNPq}^{10}$, permitiu a identificação de 160 empresas e instituições envolvidas em atividades farmacêuticas e biofarmacêuticas em saúde humana. A identificação foi realizada através da consulta dos sites institucionais das empresas e instituições. O número está sujeito a um erro de dupla contagem pois cada parceiro produtivo pode estar envolvido em interações com mais de

\footnotetext{
${ }^{7}$ Primeiro ano disponível para a série de dados.

${ }^{8}$ Último ano disponível para a série de dados.

${ }^{9}$ Fonte mais recente de dados sobre tipos de interação universidade-empresa do Diretório do CNPq.

${ }^{10}$ Dados provenientes do Censo 2010.
} 
52 Interações universidade-empresa: um estudo exploratório sobre as empresas de biotecnologia em saúde

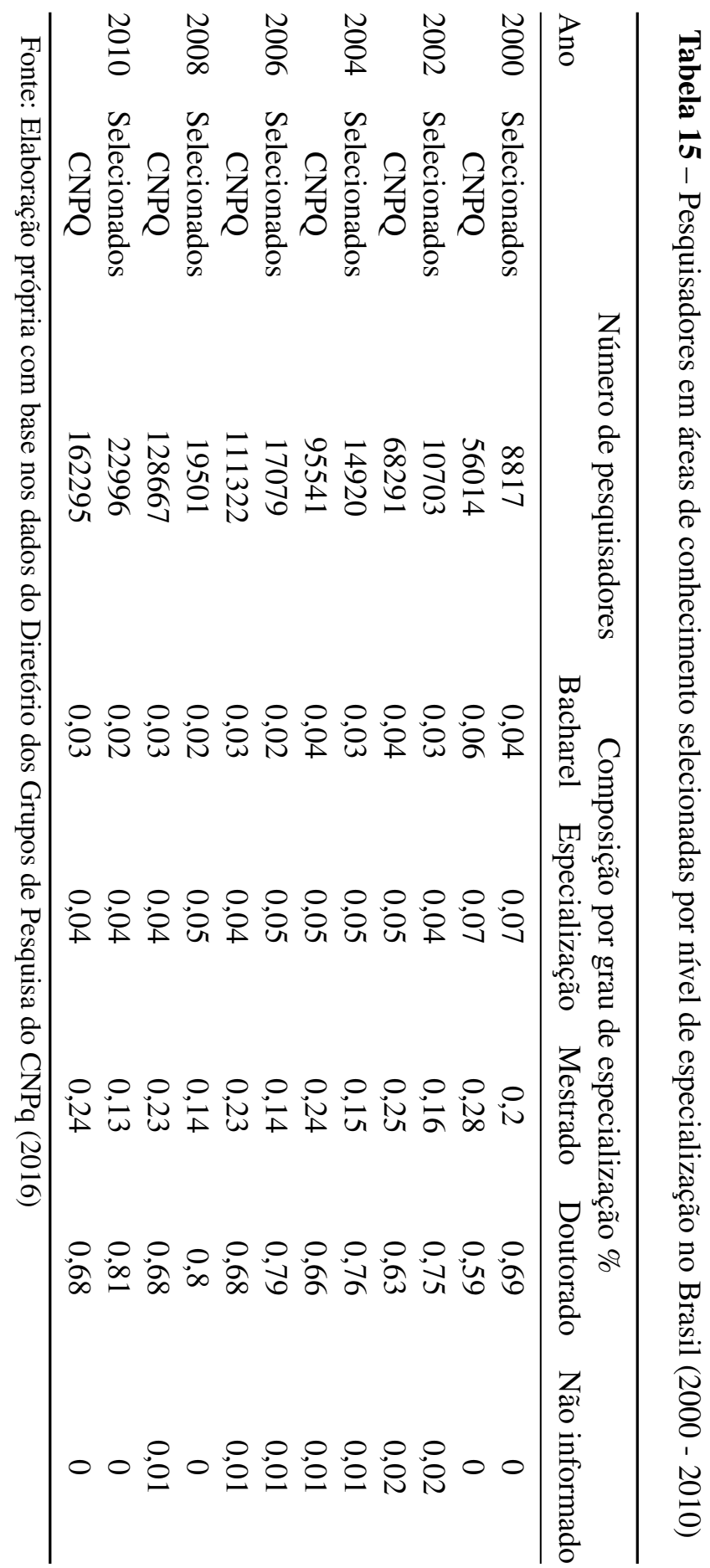

Econômica-Niterói, v. 20, n. 1, p. 31-60. Junho, 2018 


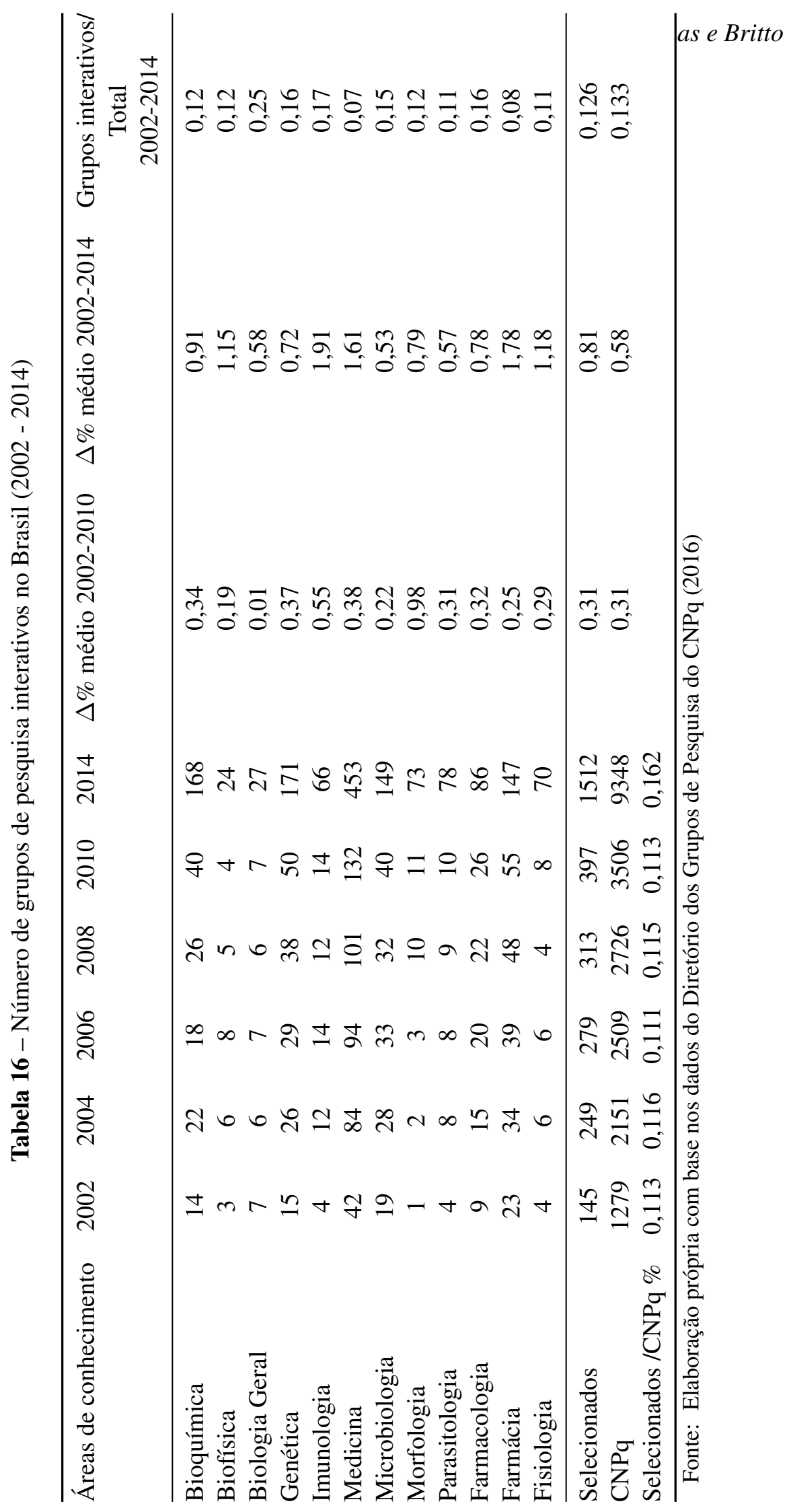

53 
$54 \quad$ Interações universidade-empresa: um estudo exploratório sobre as empresas de biotecnologia em saúde

Tabela 17 - Número de empresas e instituições interativas no Brasil (2002 2010)

\begin{tabular}{lcccccc}
\hline Áreas de conhecimento & 2002 & 2004 & 2006 & 2008 & 2010 & $\Delta \%$ médio \\
& & & & & & $2002-2010$ \\
Bioquímica & 17 & 33 & 35 & 45 & 95 & 0,6 \\
Biofísica & 4 & 7 & 11 & 8 & 5 & 0,17 \\
Biologia Geral & 9 & 8 & 8 & 11 & 13 & 0,11 \\
Genética & 28 & 51 & 59 & 73 & 89 & 0,36 \\
Imunologia & 6 & 13 & 16 & 16 & 18 & 0,38 \\
Medicina & 43 & 89 & 101 & 119 & 163 & 0,44 \\
Microbiologia & 38 & 47 & 56 & 52 & 63 & 0,14 \\
Morfologia & 1 & 3 & 4 & 12 & 15 & 1,15 \\
Parasitologia & 4 & 11 & 8 & 10 & 12 & 0,48 \\
Farmacologia & 16 & 27 & 30 & 27 & 31 & 0,21 \\
Farmácia & 33 & 49 & 64 & 72 & 101 & 0,33 \\
Fisiologia & 3 & 7 & 6 & 4 & 8 & 0,46 \\
\hline Selecionados & 202 & 345 & 398 & 449 & 613 & 0,34 \\
CNPq & 2436 & 3875 & 4534 & 5105 & 6692 & 0,3 \\
Selecionados/CNPq \% & 0,083 & 0,089 & 0,088 & 0,088 & 0,092 & \\
\hline
\end{tabular}

Fonte: Elaboração própria com base nos dados do Diretório dos Grupos de Pesquisa do CNPq (2016)

um grupo de pesquisa. A eliminação do erro de dupla contagem deu origem a uma lista com 126 empresas e instituições.

Uma limitação da base de dados foi diagnosticada durante a avaliação. A lista de empresas privadas interativas divulgada pelo CNPq não inclui apenas empresas privadas, mas também institutos de pesquisa, instituições governamentais e outras universidades. Foram excluídas da identificação empresas não dedicadas à saúde humana e empresas produtoras de fitoterápicos, devido à sua baixa complexidade tecnológica. As empresas relacionadas com ensaios clínicos, bancos de células e laboratórios de PD\&I em biofármacos e bioinformática foram incluídas na identificação devido ao seu impacto positivo na construção de competências e capacitações científicas e tecnológicas.

Entre as instituições identificadas no Censo 2010 do Diretório dos Grupos de Pesquisa do $\mathrm{CNPq}^{11}$ destaca-se a presença da Fundação Oswaldo Cruz, uma instituição de saúde pública com elevada relevância dentro do sistema farmacêutico nacional. A estrutura da Fiocruz engloba um importante laboratório oficial, o Instituto de Tecnologia em Imunobiológicos Bio-Manguinhos fundado em 1976. O instituto se destaca nas atividades de

\footnotetext{
${ }^{11}$ Considerando-se as empresas e instituições interativas nas 12 áreas de conhecimento selecionadas e nos ramos de atividade: fabricação de produtos farmoquímicos e farmacêuticos e pesquisa e desenvolvimento de científico.
}

Econômica-Niterói, v. 20, n. 1, p. 31-60. Junho, 2018 


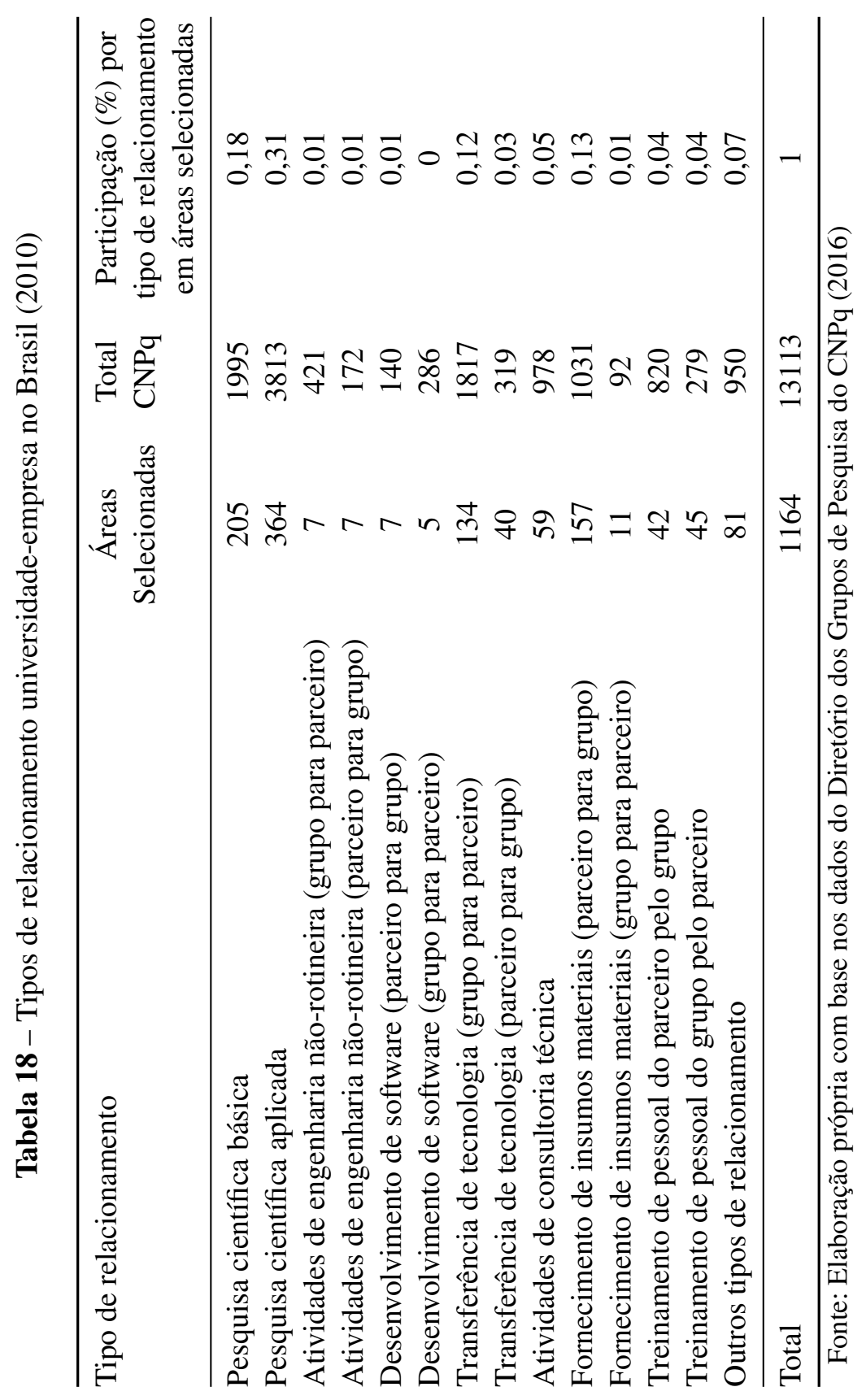

Econômica-Niterói, v. 20, n. 1, p. 31-60. Junho, 2018 
pesquisa e produção de vacinas, medicamentos, reagentes e kits de diagnóstico para atender as demandas da saúde pública no Brasil. Além da relevância nacional, o laboratório Bio-Manguinhos exporta sua produção excedente para cerca de 70 países, evidenciando o potencial para a inserção virtuosa do país na produção de biológicos ${ }^{12}$.

Um segundo destaque é a presença da Fundação Bio Rio, um parque tecnológico instalado dentro da Universidade Federal do Rio de Janeiro, dedicado à promoção de pesquisa, desenvolvimento e empreendimentos em biociências. Atualmente a Bio Rio abriga 41 empresas (20 na incubadora de empresas e 21 no parque tecnológico), além de possuir parcerias com cerca de 200 instituições nacionais e internacionais, representando uma importante ponte de integração entre a infraestrutura científica e tecnológica, parceiros do setor produtivo e à órgãos oficiais de fomento à tecnologia e inovação em ciências da vida $^{13}$.

Foram identificados cinco laboratórios oficiais de pesquisa e produção de fármacos e imunobiológicos: Laboratório Farmacêutico do Estado de Pernambuco, Indústria Química do Estado de Goiás Ltda, Empresa Brasileira de Hemoderivados e Biotecnologia Hemobrás, Instituto Vital Brasil e o Instituto de Tecnologia do Paraná.

Entre as empresas farmacêuticas nacionais que mantiveram relacionamentos com grupos de pesquisa do CNPq destacam-se a Aché Laboratórios Farmacêuticos, a Eurofarma Laboratórios e o Grupo EMS que são companhias listadas entre as dez maiores empresas brasileiras do setor farmacêutico (GADELHA, 2012). Entre as empresas interativas multinacionais, destacam-se nomes como Medley, Merck, Novartis e Eli Lilly do Brasil que estão entre as maiores empresas farmacêuticas do mundo (GADELHA, 2012). A identificação das atividades em biotecnologia é difícil e controversa por se tratar de uma atividade altamente interdisciplinar. Buscaram-se empresas com iniciativas em pesquisa e desenvolvimento de hormônios, antirretrovirais, biomateriais, reagentes, kits de diagnóstico, hemoderivados e pesquisas com células tronco, síntese de proteínas, desenvolvimento de anticorpos monoclonais, técnicas de DNA recombinante, medicamentos para tratamento oncológico e o desenvolvimento de fármacos e medicamentos com base em novas moléculas. Foram identificadas 26 micro e pequenas empresas brasileiras de biotecnologia, uma empresa pública (a Hemobrás) e 1 empresa multinacional de biotecnologia (Diamed Latino América). As empresas farmacêuticas, apesar de possuírem iniciativas para o desenvolvimento de produtos biotecnológicos, não foram listadas como empresas de biotecnologia porque é difícil identificar quais empresas efetivamente possuem aplicações no segmento de biológicos.

\footnotetext{
${ }^{12}$ Conforme informações públicas divulgadas no site institucional da Fundação Oswaldo Cruz (FIOCRUZ, 2016).

${ }^{13}$ Conforme informações divulgadas no site institucional da Fundação Bio-Rio.
}

Econômica-Niterói, v. 20, n. 1, p. 31-60. Junho, 2018 


\section{Considerações finais}

A sistematização de dados provenientes de estudos técnicos e acadêmicos selecionados permitiu a construção de um panorama sobre empresas brasileiras de biotecnologia e de biociências. Estima-se que existem cerca de 300 empresas de biociências e entre 175 e 240 empresas de biotecnologia no Brasil. As empresas brasileiras são: jovens; micro e pequenas; fortemente concentradas na região sudeste, especialmente no estado de São Paulo e Minas Gerais; especializadas na provisão de serviços biotecnológicos ou desenvolvedoras de produtos e processos; em fase pré-operacional e controladas majoritariamente por capital nacional. Outras características apontadas são: a forte relação com universidades e centros de pesquisa acadêmica e o elevado coeficiente de empresas incubadas e graduadas. As empresas voltadas à saúde humana correspondem a cerca de $40 \%$ das empresas identificadas pelos estudos revisados, representando a área de atividade com a maior concentração de empresas

As características apontadas permitem associar as empresas brasileiras de biotecnologia e biociências ao modelo de Science Based Business - também referenciado como empresas de base tecnológica ou empreendimentos intensivos em conhecimentos - que são empresas criadas para explorar peças de conhecimento acadêmico ou tecnológico através do modelo de start-ups tecnologicas ou spin-offs acadêmicos. Destaca-se, portanto, o eminente caráter "baseado em ciência" das atividades intensivas em biotecnologia no Brasil.

$\mathrm{O}$ arcabouço de colaborações e divisão do trabalho inovador dentro do ambiente sistêmico de inovação em biociências para saúde humana assumem no Brasil um formato particular. No caso brasileiro, observa-se a participação de cinco elementos principais ICTs, laboratórios oficiais, empresas de biotecnologia, empresas farmacêuticas nacionais e multinacionais - no âmbito de um sistema setorial marcado pela existência do SUS e pela participação ativa do governo como articulador do sistema de inovação em saúde. $O$ sistema de inovação mostra-se mais intensivo em articulações universidade-empresa do que em acordos para transferência de tecnologia entre empresas privadas. Destacam-se os esforços recentes adotados pelo governo brasileiro na promoção de alianças de cooperação para transferência tecnológica entre empresas farmacêuticas privadas e laboratórios oficiais visando a nacionalização da produção de fármacos e medicamentos produzidos por rota biotecnológica através da promoção de um ambiente sistêmico integrado e colaborativo.

O Brasil possui ampla gama de instituições de ciência e tecnologia com grupos de pesquisa consolidados em áreas de conhecimento sensíveis para o fortalecimento e para a consolidação das atividades que compõem a cadeia de PD\&I biofarmacêutica no país. O número de grupos de pesquisa, linhas de pesquisa e pesquisadores dessas áreas de conhecimento é crescente, assim como a proporção de pesquisadores altamente qualificados nos grupos de pesquisa. O país apresenta um quadro condizente com um aumento das 
interações universidade-empresa nas áreas de conhecimento selecionadas. Os tipos mais frequentes de relacionamentos foram esforços conjuntos de pesquisa básica e aplicada e transferências diretas de tecnologia entre grupos de pesquisa e parceiros do setor produtivo. Apesar da importância das atividades de formação de pessoal e pesquisa básica pelas universidades, as atividades conjuntas de pesquisa aplicada e transferência tecnológica são indicadores da atuação ativa das instituições acadêmicas brasileiras no empreendedorismo acadêmico e no fomento de inovações no setor privado.

A avaliação sobre o perfil das empresas envolvidas nas interações universidade-empresa revelou uma amostra de empresas e instituições ampla e diversificada que abrange todos os principais componentes do sistema setorial de inovação farmacêutica brasileira. A análise dos dados revelou a presença de laboratórios oficias e de instituições de apoio ao desenvolvimento científico e tecnológico na lista de empresas e instituições que mantiveram relacionamentos com os grupos de pesquisa do CNPq no ano 2010, entre eles a Fundação Oswaldo Cruz e Instituto BioRio. A grande diversidade de atores integrantes do sistema setorial farmacêutico brasileiro parece corroborar a hipótese levantada por Cassiolato e Albuquerque (2002) de que as universidades atuam como um importante elo de convergência de informações e articulações nos sistemas de inovação em saúde humana. Apesar da expressiva evolução dos indicadores de interações entre a esfera acadêmica e o setor produtivo, a comparação entre os indicadores de estrutura científica e indicadores de interação revela que ainda existem gargalos significativos a serem superados para garantir o sucesso na transferência de conhecimentos científicos ao setor produtivo e estimular o desenvolvimento de inovações farmacêuticas e biofarmacêuticas no Brasil.

\begin{abstract}
The objective of this article is to present an overview of the biotechnology and bioscience companies established under the model of knowledge - intensive enterprises in Brazil and their interactions with the Brazilian structure of Science and Technology in the areas of biological and health sciences. The study is structured in five sections dedicated to defining biotechnology and its "science-based"character, to characterize the emerging biotechnology industry in Brazil, to present the evidences of incorporation of modern biotechnology by the pharmaceutical industry in Brazil, to point out the characteristics of the structure of science and technology in the areas of knowledge related to biotechnology in human health and to present evidences of universitycompanies interactions in this segment in Brazil. The analysis is based on data from different studies, complemented by information extracted from the National Directorate of Research Groups of the National Council for Scientific and Technological Development (CNPq) for the period 2000 and 2014. The results indicate the existence of about 300 bioscience companies and 200 biotechnology companies in Brazil, of which $40 \%$ on average are involved in human health activities. The companies are young, small, mostly controlled by national capital and located in the southeastern region of Brazil, most of them in the pre-operational stage or involved in the provision of technological services. There are also indications that these companies are strongly articulated to universities and research centers in Brazil.
\end{abstract}

Econômica-Niterói, v. 20, n. 1, p. 31-60. Junho, 2018 
Keywords: Biotechnology, Biosciences, Knowledge-based intensive enterprises, Human health JEL: L26, L65, O15.

\section{Referências bibliográficas}

ABDI, A. B. d. D. I. Biotecnologia no Brasil. Sumário Executivo. 2012.

ABDI, A. B. d. D. I. Incorporação da rota brasileira biotecnológica na indústria farmacêutica brasileira: desafios e oportunidades. Relatório de acompanhamento setorial. 2013.

ALBUQUERQUE, E.; CASSIOLATO, J. E. As especificidades do sistema de inovação do setor saúde. Revista de Economia Política, v. 22, n. 4, p. 134-151, 2002. Disponível em: <http://www.scielo.br/scielo.php?script=sci $\_n l i n k s \& r e f=000141 \&$ pid= S1413-8050200600040000300003\&lng=pt>.

BIANCHI, C. A Indústria Brasileira de Biotecnologia: montando o quebracabeça. Revista Economia \& Tecnologia, v. 9, n. 2, 2013. Disponível em: $<$ http://revistas.ufpr.br/ret/article/view/30907>.

Biominas. Parque nacional de empresas de biotecnologia. Belo Horizonte: Fundação Biominas, 2001.

Biominas. Estudo de empresas de biotecnologia do Brasil. [S.1.]: Fundação Biominas, 2007.

Biominas. Estudo de empresas de biociências do Brasil 2009. [S.1.]: Fundação Biominas, 2009.

Biominas e PwC. A indústria de biociências nacional: caminhos para o crescimento. Biominas Brasil e PricewaterhouseCoopers, 2011. Disponível em: <http://www.scielo. br/scielo.php?script=sci _nlinks\&ref=000159\&pid=S0101-3300201400010000500011\& $\operatorname{lng}=\mathrm{pt}>$.

BRASIL, G. F. LEI COMPLEMENTAR No 123, DE 14 DE DEZEMBRO DE 2006. Brasília: Poder Executivo, 2006. Disponível em: <http://www.planalto.gov.br/ccivil $\_03 /$ leis/LCP/Lcp123.htm>.

BRINK, J.; MCKELVEY, M.; SMITH, K. Conceptualizing and measuring modern biotechnology. In: BRINK, J.; MCKELVEY, M.; SMITH, K. (Ed.). The Economics 
60 Interações universidade-empresa: um estudo exploratório sobre as empresas de biotecnologia em saúde

Dynamics of Modern Biotechnology. Edward Elgar Publishing, 2004. p. 20-42. Disponível em: <https://eprints.utas.edu.au/1388/>.

CEBRAP, C. B. d. A. e. P.; BRBIOTEC, A. B. d. B. Brazil Biotech Map 2011. São Paulo: Brazil Biotech Map 2011, 2011.

DI GREGORIO, D. et al. Research policy. Research Policy, Elsevier Science Publishers B.V. (North-Holland), v. 32, n. 2, p. 209-227, 2003. Disponível em: <https://econpapers. repec.org/article/eeerespol/v\_3a32\_3ay\_3a2003\_3ail_3a2\_3ap\_3a209-227.htm>.

ELIASSON, G.; ELIASSON, A. The biotechnological competence bloc. Revue d'économie industrielle, Persée - Portail des revues scientifiques en SHS, v. 78, n. 1, p. 7-26, 1996. Disponível em: <https://www.persee.fr/doc/rei\_0154-3229\_1996\num\ _78\_1\_1641>.

ETZKOWITZ, H.; LEYDESDORFF, L. The dynamics of innovation: from National Systems and "Mode 2" to a Triple Helix of university-industry-government relations. Research Policy, North-Holland, v. 29, n. 2, p. 109-123, 2 2000. Disponível em: $<$ https://www.sciencedirect.com/science/article/pii/S0048733399000554>.

FIOCRUZ, F. O. C. Fundação Oswaldo Cruz: uma instituição a serviço da vida. 2016. Disponível em: <http://portal.fiocruz.br/pt-br>.

GADELHA, C. A. G. A dinâmica do sistema produtivo da saúde : inovaąão e complexo econômico-industrial. Rio de Janeiro: Editora Fiocruz, 2012. 221 p. ISBN 9788575414187. Disponível em: <https://portal.fiocruz.br/livro/ dinamica-do-sistema-produtivo-da-saude-inovacao-e-complexo-economico-industrial $>$.

GIBBONS, M.; JOHNSTON, R. The roles of science in technological innovation. Research Policy, North-Holland, v. 3, n. 3, p. 220-242, 11 1974. Disponível em: <https://www.sciencedirect.com/science/article/pii/0048733374900080>.

KLEVORICK, A. K. et al. On the sources and significance of interindustry differences in technological opportunities. Research Policy, North-Holland, v. 24, n. 2, p. 185-205, 3 1995. Disponível em: <https://www.sciencedirect.com/science/article/pii/ $004873339300762 I>$.

MAZZUCATO, M.; DOSI, G. Introduction. In: MAZZUCATO, M.; DOSI, G. (Ed.). Knowledge accumulation and industry evolution : the case of Pharma-Biotech. [S.1.]: Cambridge University Press, 2006. p. 446. ISBN 9780521858229.

MCKELVEY, M.; ORSENIGO, L. Pharmaceuticals as a Sectoral Innovation System. 2001 . 
MOWERY, D. C.; SAMPAT, B. N. Universities in National Innovation Systems. In: FAGERBERG, J.; MOWERY, D. C.; NELSON, R. R. (Ed.). The Handbook of innovation. Oxford University Press, 2006. Disponível em: <http://oxfordhandbooks. com/view/10.1093/oxfordhb/9780199286805.001.0001/oxfordhb-9780199286805-e-8>.

OCDE, O. p. a. C. e. D. E. A framework for biotechnology statistics. 2005.

ORSENIGO, L.; PAMMOLLI, F.; RICCABONI, M. Technological change and network dynamics. Research Policy, v. 30, n. 3, p. 485-508, 3 2001. Disponível em: <http://linkinghub.elsevier.com/retrieve/pii/S0048733300000949>.

PARANHOS, J. Interação entre empresas e instituições de ciência e tecnologia: o caso do sistema farmacêutico de inovação brasileiro. Rio de Janeiro: EdUERJ, 2012.

PAVITT, K. Sectoral Patterns of Technical Change: towards taxonomy and a theory. Research Policy, n. 13, p. 343-374, 1984.

PISANO, G. The Evolution of Science-Based Business: Innovating How We Innovate. 2010.

SHANE, S. Academic entrepreneurship : university spinoffs and wealth creation. [S.1.]: E. Elgar, 2004. 335 p. ISBN 184542221X.

VARGAS, M.; et al. Indústrias de base química e biotecnológica voltadas para a saúde no Brasil: panorama atual e perspectivas para 2030. In: A saúde no Brasil em 2030 prospecção estratégica do sistema de saúde brasileiro: desenvolvimento produtivo e complexo da saúde. 22. ed. Rio de Janeiro: Editora Fiocruz, 2013.

VARGAS, M.; et al. Innovation and competence building in biopharmaceuticals in Brazil: implications for public policy. In: . Montreal: 16o International Joseph A. Schumpeter Society Conference, 2016. 